\title{
An Analysis of the Early and Periodic Screening, Diagnostic, and Treatment Benefit:

\author{
Implications for the Healthcare of \\ Children in Foster Care
}

Jae-Marie Ferdinand

\begin{abstract}
he Early and Periodic Screening, Diagnostic, and Treatment (EPSDT) benefit mandates full coverage of healthcare for children enrolled in Medicaid. The EPSDT benefit provides the access, framework, resources, and financing for healthcare for children with complex healthcare needs. When fully implemented, the EPSDT benefit leads to improved health outcomes. This paper examines the EPSDT benefit as an essential healthcare resource for vulnerable children, notably children in foster care. The majority of children in foster care receive Medicaid healthcare coverage and have complex healthcare needs. According to the most recent research, many children in foster care are not receiving this mandated benefit. Improved implementation of the EPSDT benefit is key to improving health outcomes. This policy analysis reviews the EPSDT benefit, evidence for its effectiveness, issues challenging full implementation for children in foster care, examples of successful implementation, and provides recommendations for improved implementation. Specific recommendations include coordination of healthcare and child welfare services (e.g. with health services coordinators), increased accountability for implementers, and adequate numbers of qualified, trauma-informed providers.
\end{abstract}




\section{INTRODUCTION}

THE EARLY AND PERIODIC SCREENING, DIAGNOSTIC, AND TREATMENT BENEFIT

The Early and Periodic Screening, Diagnostic, and Treatment (EPSDT) benefit is a federal benefit program under Medicaid that provides health care entitlement services for children who are enrolled in Medicaid (CMS, n.d.[a]). Each state administers its own EPSDT program, which is financed by funds from both the state and the federal government. To comply with the benefit mandate, states are required to inform families of the benefit and ensure that children are screened and receive appropriate diagnosis, treatment, services, and adequate follow-up. Appropriate diagnosis, treatment and services are targeted to the healthcare problem. Adequate follow-up implies following the child closely to ensure proper progress to achieve their healthcare goals. States are also required to report results of their compliance to the Centers for Medicare \& Medicaid Services (CMS) annually (CMS, n.d.[a]; CMS, n.d.[b]; CMS 2014).

The EPSDT benefit addresses the problem of insufficient access to appropriate clinical care for children who are at an increased risk for poor health and psychosocial outcomes, including prevention, screening, treatment and adequate follow-up by covering children eligible for Medicaid, who are often at higher risk (CMS 2014). The goal of the EPSDT benefit is to prevent or treat healthcare problems as early as possible (early intervention) (CMS, n.d.[b]; MACPAC, n.d.). The EPSDT benefit program provides for the screening and prevention guidelines based on professional standards (CMS, n.d.[a]; CMS, n.d.[b]; CMS 2014). States may use the American Academy of Pediatrics guidelines "Bright Futures" for well child visits, or they may use guidelines from other professional organizations (CMS, n.d.[a]; CMS 2014). Through mandated annual reporting of services provided, the EPSDT addresses the issue of insufficient access to healthcare for eligible children, and CMS can track state compliance (CMS, n.d.[a]; GAO 2009).

According to the Medicaid Annual Reporting Data Files for Fiscal Year 2018, more than 42 million children were eligible for the EPSDT benefit, yet fewer than 60 percent of these children received at least one initial or periodic screening (CMS, n.d.[c]). A US Government Accountability Office (GAO) report identified a similar rate for fiscal year 2017, noting a five-percentage point decline since 2010 (GAO 2019).

\section{CHILDREN IN FOSTER CARE AND THE EPSDT BENEFIT}

Foster care is a system for children who can no longer live with their primary caregivers (usually biological parents). As a result, these children are cared for by adults outside of their home. Foster care can be provided by relatives, or non-relative adults, or in residential facilities, such as group homes (Child Welfare Information Gateway, n.d.).

Children in foster care have a much higher prevalence of health problems than comparable counterparts who are not in foster care (American Academy of Pediatrics 2005). These children have complex healthcare needs, stemming from the trauma they sustained prior to placement, preplacement medical conditions, the emotional trauma of being removed from their home, and the fact that they often receive care from multiple healthcare providers and caregivers. Proper medical, developmental, and psychosocial follow-up, and continuity of care are often missing (American Academy of Pediatrics 2005). Proper developmental follow-up includes 
assessing children for the presence of age-appropriate milestones, making recommendations (either for the caregiver to implement, or for further investigation and referral to specialists), and providing guidance and suggestions to caregivers about the child's next milestone. This could include providing guidance on early literacy and school readiness practices or programs (Williams and Lerner 2019).

Almost all children in foster care are eligible for Medicaid (American Academy of Pediatrics 2005; Child Welfare Information Gateway 2015), therefore should be receiving the full range of EPSDT benefits. Despite this, a 1995 GAO report showed one-third of children in foster care did not have their healthcare problems addressed while in care (GAO 1995). Fragmentation of care - i.e., when children's healthcare lacks continuity or consists of many different, disconnected healthcare providers and care takers - leads to a lack of knowledge about the children's healthcare needs by both healthcare providers and care takers (American Academy of Pediatrics 2005). Once children have access to healthcare, decisions about their care are made by multiple decision makers, further complicating healthcare provision. These multiple decision makers may include the biological and foster parents, child welfare representatives, and legal representatives (American Academy of Pediatrics 2005).

\section{SYSTEM ACCOUNTABILITY}

The EPSDT benefit provides access to needed healthcare, as well as a legal framework, funding, and system accountability to holistically address the complex healthcare needs of children in foster care. However, many children in foster care are not obtaining the full EPSDT benefits that they are eligible for (GAO 1995), which some healthcare providers suggest the lack of coordination between care providers may contribute to (Ruptier 1997). Caregivers and caseworkers may not be aware of the EPSDT benefit (Department of Health and Human Services Office of Inspector General 2003; CMS, n.d.[b], 1). Other issues that may contribute to the gap between these children's healthcare needs and access to the benefit include a lack of access to specialty service providers, and lack of enforced system accountability (Allen and Hendricks 2013). An accountability system is one in which an overseeing body ensures that service provision meets an appropriate standard and provides an enforcement mechanism in the case that services do not meet that standard. In the case of the EPSDT benefit, states are required to report proof that they have appropriately implemented the EPSDT benefit for all eligible children to the Center for Medicare \& Medicaid Services (CMS), who oversees the program (CMS, n.d.[a]; GAO 2019). To be enforced, this closed-loop EPSDT system accountability requires oversight by CMS (GAO 2019).

This paper will review the evidence for the EPSDT program's effectiveness and the issues challenging full implementation for children in foster care. Then, it will identify key components of successful benefit programs for foster care youth and, finally, recommend ways to improve healthcare coverage for children in foster care.

\section{BACKGROUND}

\section{HISTORY OF THE EPSDT BENEFIT}

The EPSDT benefit was included in the Social Security Amendments of 1967 as a mandatory Medicaid benefit. It was enacted in response to research that revealed young men 
drafted into the military were being disqualified at high rates due to childhood illnesses that were left untreated (Rosenbaum et al. 2005). In 1989, Congress significantly expanded the EPSDT coverage to codify the benefit, encompassing key aspects of healthcare (Goldstein 2013). These key aspects of healthcare included specification of the physical, developmental, and psychosocial care paid for by the benefit, and associated supportive levels of care. Examples of these levels of care include laboratory services (e.g. checking lead levels), physical and occupational therapy, immunizations, and recommended dental care (Rosenbaum 2016).

The EPSDT was intended to provide mandated, comprehensive healthcare coverage to low-income children to prevent and treat childhood illnesses early, improving child health and ensuring each child could reach their full potential. The program was designed to improve children's health by providing increased access to medical care, including preventative and early intervention services for eligible children (Rosenbaum 2016). As the EPSDT benefit was funded as a part of Medicaid, this approach covered the population of children deemed most vulnerable (Rosenbaum 2017).

\section{HEALTH OF CHILDREN IN FOSTER CARE}

The American Academy of Pediatrics notes that the foster care system should "provide for the health, safety, and well-being of children, while fostering family reunification or an alternative permanency arrangement, when reunification is not possible" (Council on Foster Care, Adoption, and Kinship Care, the Committee on Adolescence, and the Council On

Early Childhood 2015). According to the Adoption and Foster Care Analysis and Reporting System (AFCARS) estimates, over 600,000 children spent time in foster care in 2017. The main reasons associated with removal from the home and placement into the foster care system included neglect, abuse, and parental substance abuse (Administration for Children and Families 2018).

A majority of children already suffer from a diagnosable health care condition when placed in foster care (Leslie et al. 2005; Chernoff et al. 1994; Hochstadt et al. 1987), and as many as 40 percent of children in the child welfare system are affected with chronic or complicated health issues (Ringeisen et al. 2008; Jee et al. 2006; Takayama, Wolfe, and Coulter 1998; Hochstadt 1987, 55-59). Diagnosable implies these health care concerns have been present prior to placement but may or may not have been addressed or identified by a healthcare provider. The healthcare problems may be related to oral or medical conditions (e.g. tooth decay, asthma), mental health conditions (e.g. depression), or delays in the child's growth, development, and educational level (American Academy of Pediatrics 2005; Hochstadt et al. 1987). Many of these diagnosable conditions are preventable or amenable to early intervention (e.g. tooth decay, asthma). In addition, almost all children placed in foster care have psychosocial problems (Hochstadt 1987), which has been attributed to the combination of factors that led to removal from their home and placement into foster care (Simms, Dubowitz, and Szilagyi 2000; Hillen and Gafson 2015). Research reveals that children who experience foster care are at high risk for persistent health problems, mental health conditions related to their trauma (e.g. posttraumatic stress disorder); are unable to reach their educational potential, gain sustainable employment, or maintain a home; and are more likely to be involved with the criminal justice system (Reilly 2003; Cutuli et al. 2016). Screening, preventative strategies, and early interventions are measures that can lead to improved health, and enhanced quality of life outcomes (Pandve 2014). 


\section{IMPORTANT LEGISLATION IMPACTING THE HEALTH CARE OF FOSTER CHILDREN}

The Fostering Connections to Success and Increasing Adoptions Act of 2008 (sec. 2015) mandates improved communication and coordination between state child welfare agencies and state Medicaid agencies by developing healthcare plans for each child. These plans should include all of the needed healthcare services, a method of sharing this information with relevant healthcare providers and child welfare agencies, and an oversight mechanism.

The Affordable Care Act (ACA) of 2010 expands the existing 1915(i) state option provision of the Social Security Act, giving states greater flexibility to provide services in the home or community (Lehmann, Guyer and Lewandowski 2012). These services would allow for improved implementation and coordination by simplifying access and allowing for management closer to where the child resides and attends school.

Finally, the Child and Family Services Improvement and Innovation Act of 2011 mandates each state to develop a plan outlining the management of the child's healthcare services to include services for emotional trauma associated with the reasons for their foster care placement (sec. 101). Together, these acts provide states with legal frameworks to improve their use of the EPSDT benefit when providing services to the foster care community by facilitating improved communication, coordination, monitoring, and oversight of the services provided by the EPSDT benefit.

\section{BARRIERS TO ACCESSING THE EPSDT BENEFIT}

The EPSDT benefit supports and finances many preventative and early intervention services (CMS 2014, CMS, n.d.[b]). However, several barriers exist that prevent children from fully benefitting from the EPSDT benefit. These barriers may be related to the child welfare system, the healthcare system, or lack of coordination of services amongst both healthcare providers and child welfare workers. Child welfare system barriers may include a lack of awareness about benefits by child welfare providers, foster caregivers and biological parents, as well as involvement by multiple people (such as caregivers, social service providers, educators, and legal representatives) with differing decision-making capabilities who are unaware of the child's complete health history and needs. Discontinuity of services due to placement moves and changes in staff (e.g., healthcare, social services, childcare and school-related) may also occur. Healthcare system barriers may be due to foster care children not having adequate access to healthcare services or care providers familiar with their specific needs (Szilagyi, Rosen, and Rubin 2015; Halfon and Klee 1987; McGill 2016; MACPAC 2015; American Academy of Pediatrics 2005; Allen and Hendricks 2013; Rubin, n.d.).

Because the EPSDT benefit has been inadequately implemented for children in foster care and demonstrates a lack of service coordination, the children who need the services provided by the benefit are not receiving them (GAO 1995; GAO 2019). Children who are receiving the benefits are often receiving services and treatments that are uncoordinated due to poor communication systems, leading to inadequate or improper services (Szilagyi, Rosen, and Rubin 2015). However, health service coordinators have been shown to facilitate improved implementation and coordination of services (Pires and Stroul 2013). 
Accountability across service providers, child welfare agencies, and government agencies is necessary to address the inadequate implementation rates and lack of proper coordination (American Academy of Pediatrics 2005). For many of these entities, there is little incentive to ensure full access to the range of EPSDT benefits for foster care children, as the benefit is costly and complex to administer, and service providers are not adequately compensated for the level of care required (American Academy of Pediatrics 2005; Allen and Hendricks 2013; Committee on Early Childhood, Adoption, and Dependent Care 2002).

\section{EXAMPLES OF EFFECTIVE IMPLEMENTATION STRATEGIES}

Certain states have developed effective implementation strategies to ensure access to the EPSDT benefit and the health improvements it provides, demonstrating a range of approaches and best practices (Pires and Stroul 2013). The State of Tennessee's policies and procedures require integration of the EPSDT guidelines into every step of their placement process and throughout children's time and care. As a result, 95 percent of the children in the care of the Tennessee Department of Children's Services received medical screenings and 85 percent received dental care according to the EPSDT guidelines in 2014 (Tennessee Department of Children's Services 2015).

Michigan's Child Welfare System has "health liaison officers" who work with the foster care agencies, Medicaid, and foster families to ensure proper enrollment into the EPSDT benefit program, and proper access to the screening and continuity of physical healthcare services throughout the child's placement in care. Mental health clinicians play a complementary role as "access staff," coordinating these children's mental healthcare services (Pires and Stroul 2013). Children who enter the child welfare system in Massachusetts, Texas, and San Diego, California, are given "medical passports" which support consistency and information-sharing across medical providers, foster families, and child welfare workers (Pires and Stroul 2013; San Diego County 2017; Ruptier 1997).

Several states have also implemented policies to incentivize specialized practitioners to offer services to eligible foster care youth. Arizona has a special Medicaid health plan for children in foster care financed through a risk-adjusted capitation rate. This means that rates paid to behavioral health authorities have been adjusted for risk and are on average 29 percent higher than rates for children outside of the welfare system. New Jersey's Medicaid and child welfare agencies have higher healthcare provider rates for the comprehensive medical examinations at initial placement. In order to expand behavioral health services for children in foster care, Arizona and Michigan match state child welfare funds with federal Medicaid funds (Pires and Stroul 2013).

\section{RECOMMENDATIONS AND FRAMEWORK FOR IMPROVED PRACTICE}

Improving EPSDT implementation for foster care children will require a call to action by state and federal governments, child welfare, and healthcare agencies, resulting in a more responsive and comprehensive health care system for foster children. The primary recommendation of this paper is to establish health service coordinators and implement health care passports for every child in foster care. Additional recommendations include 
improving system accountability and increasing the number of healthcare providers who are skilled in caring for foster care children, by improving retention and attracting new skilled providers.

Significant collaboration will be required between a variety of entities to implement and secure funding for these recommendations. For example, foster care and healthcare agencies can work together to implement health care passports and develop the role of health service coordinators. Funding and system accountability will require collaboration at all levels, including between state agencies and Medicaid. Improving retention and attracting new skilled providers will require funding and collaboration between professional provider organizations and government funding agencies.

The most direct path to a more effective use of the EPSDT benefit would be training, hiring, and obtaining funding for the training and hiring of professional healthcare coordinators who can accompany every child from the time of placement until they exit foster care in order to navigate the system, advocate for the child, and ensure proper access to appropriate services. Ideally, the healthcare professional would be a nurse specialized in the needs of children in foster care, the EPSDT benefit, and other important aspects of care.

To ensure accurate and updated healthcare information is provided to all professionals responsible for a child's care, social workers and healthcare providers should work with foster parents to develop, maintain, and safeguard a health care passport for each child. For example, the Massachusetts Department of Children and Families, the Texas Department of Family and Protective Services, and the San Diego County Department of Social Services provide healthcare passports for children in foster care. These passports provide important healthcare information in a portable format for easy access by all healthcare providers. This ensures proper healthcare and follow-up, and prevents duplication of unnecessary services and treatments (Pires and Stroul 2013; Child Welfare Information Gateway 2015; Texas Department of Family and Protective Services, n.d.; Ruptier 1997).

Economically and politically, providing adequate funding for individual health care coordinators and healthcare passports will be a challenge, as implementation and ongoing management will require significant funding. However, these programs have been highlighted as potential cost-effective innovations, as they improve prevention and early intervention rates, leading to a decrease in costs related to treating foster children's chronic health problems (Piers and Stroul 2013; Ruptier 1997).

Improvements can be made to address current issues with accountability as well. The presence of health service coordinators would help ensure that children who need the services are receiving them. State-level accountability oversight mechanisms should be implemented. One potential deterrent for non-compliance at the state level are monetary penalties, although imposing and enforcing penalties will be challenging. The federal government could collect these penalties into a fund to pay for services not provided under the EPSDT benefit (e.g. therapeutic foster care), foster care focused education, and outreach to service providers related to the EPSDT benefit program.

Education and outreach may improve information sharing between healthcare providers, child welfare workers, and foster parents. Education and outreach topics could include 
health issues particular to children in foster care, the importance of primary and secondary prevention, and information specific to the optimal utilization of the EPSDT benefit.

Increasing funding to train healthcare providers in the specific needs of children in foster care, as well as increased service reimbursement rates for providers of healthcare to children in foster care would attract more qualified, well-trained service providers. Healthcare professionals, their organizations, and academic institutions should be involved in developing educational material specific to the needs of children in foster care (e.g. American Academy of Pediatrics, American Academy of Pediatric Dentistry). For example, New Jersey has two key pathways for foster care-related continuing education and training. The Child Welfare Training Academy and the Behavioral Health Research and Training Institute both provide training in partnership with Rutgers University for practitioners (Rutgers, The State University of New Jersey, n.d.; Rutgers Health, n.d.).

\section{CONCLUSION}

The EPSDT benefit is a federally mandated comprehensive benefit that holistically addresses the healthcare needs of vulnerable children, particularly children in foster care. Children in foster care often have complex health, developmental, and psychosocial impairments. Currently, the EPSDT benefit is underutilized for children in foster care for a variety of reasons. These reasons include inadequate health service coordination between families, child welfare agencies, healthcare providers and Medicaid, insufficient healthcare providers skilled in the care of children in foster care, and inadequate system accountability. This leads to a lack of access to appropriate health and psychosocial services for foster care children. Many of the health, developmental, and psychosocial conditions these children experience are amenable to prevention and early intervention measures, which would be addressed through appropriate implementation of the EPSDT benefit.

In order for these children to reach their potential, the EPSDT services should be fully accessible to every child entering foster care, and states should be held accountable for mandating access. The Center for Medicare \& Medicaid Services, healthcare providers and child welfare workers should work together to ensure proper implementation of the EPSDT benefit. Health service coordinators may facilitate communication and coordination. Increased accountability for implementers, and adequate numbers of qualified, traumainformed providers are also necessary factors to optimize the implementation of EPSDT services for all children in foster care.

\section{REFERENCES}

Administration for Children and Families. 2018. “AFCARS Report \#25." Children’s Bureau. Accessed April 26, 2019. https://www.acf.hhs.gov/cb/resource/afcars-report-25.

Allen, Kamala D., and Taylor Hendricks. 2013. Medicaid and Children in Foster Care. Hamilton: Center for Health Care Strategies. https://www.chcs.org/resource/medicaid-and-children-in-foster-care/. 
American Academy of Pediatrics. 2005. Fostering Health: Health Care for Children and Adolescents in Foster Care. 2nd ed. New York: American Academy of Pediatrics.

Berger, Lawrence M., Sarah K. Bruch, Elizabeth I. Johnson, Sigrid James, and David Rubin. 2009.

"Estimating the 'Impact' of Out-of-Home Placement on Child Well-Being: Approaching the Problem of Selection Bias: Impact of Out-of-Home Placement on Child Well-Being." 2009. Child Development 80, no. 6 (November): 1856-76. https://doi.org/10.1111/j.1467-8624.2009.01372.x.

Chernoff, R., Terri Combs-Orme, Christina Risley-Curtiss and Alice Heisler. 1994. "Assessing the Health Status of Children Entering Foster Care." Pediatrics 93 (4): 594-601.

Child Welfare Information Gateway. 2015. Health-Care Coverage for Youth in Foster Care-and After. Washington DC: US Department of Health and Human Services, Children's Bureau. https://www. childwelfare.gov/pubs/issue-briefs/health-care-foster/.

---. n.d. "Foster Care." Child Welfare. Accessed January 20, 2020. https:/www.childwelfare.gov/topics/ outofhome/foster-care/.

CMS (Center for Medicare \& Medicaid Services). 2014. EPSDT - A Guide for States: Coverage in the Medicaid Benefit for Children and Adolescents. Washington DC: Center for Medicare \& Medicaid Services. https://www.dhhs.nh.gov/ombp/medicaid/mts/documents/epsdtcoverageguide.pdf.

---. n.d.(a). "Early and Periodic Screening, Diagnostic, and Treatment." Medicaid. Accessed April 5, 2019. https://www.medicaid.gov/medicaid/benefits/early-and-periodic-screening-diagnostic-andtreatment/index.html.

---. n.d.(b). "Early and Periodic Screening." In The State Medicaid Manual. Washington DC: Center for Medicare \& Medicaid Services. https://www.cms.gov/Regulations-and-Guidance/Guidance/ Manuals/Paper-Based-Manuals-Items/CMS021927.

---. n.d.(c). "Annual EPSDT Reporting Using the Form CMS-416: Annual Reporting Data Files FY 2018 Data." Early and Periodic Screening, Diagnostic, and Treatment. Accessed January 20, 2019. https://www.medicaid.gov/medicaid/benefits/early-and-periodic-screening-diagnostic-andtreatment/index.html.

Committee on Early Childhood, Adoption, and Dependent Care. 2002. "Health Care of Young Children in Foster Care." Pediatrics 109 (3): 536-541; DOI: https://doi.org/10.1542/peds.109.3.536

Council on Foster Care, Adoption, and Kinship Care, the Committee on Adolescence, and the Council On Early Childhood. 2015. "Health Care Issues for Children and Adolescents in Foster Care and Kinship Care.” Pediatrics 136, no. 4 (October): e1131-40. https://doi.org/10.1542/peds.2015-2655.

Cutuli, J.J., Robert M. Goerge, Claudia Coulton, Maryanne Schretzman, David Crampton, Benjamin J. Charvat, Nina Lalich, JessicaA. Raithel, Cristobal Gacitua, and Eun Lye Lee. 2016. "From Foster Care to Juvenile Justice: Exploring Characteristics of Youth in Three Cities." Children and Youth Services Review 67 (August): 84-94. https://doi.org/10.1016/j.childyouth.2016.06.001.

Department of Health and Human Services Office of Inspector General. 2003. Foster Care Children's Use of Medicaid Services in New Jersey. The Department of Health and Human Services. https://oig.hhs. gov/oei/reports/oei-02-00-00360.pdf

Goldstein, Melissa M., and Sara Rosenbaum. 2013. "From EPSDT to EHBs: The Future of Pediatric Coverage Design Under Government Financed Health Insurance." Pediatrics 131, no. S2 (April): S142-48. https://doi.org/10.1542/peds.2013-0252e.

GAO (Government Accountability Office). 1995. Foster Care: Health Needs of Many Young Children Are Unknown and Unmet. Washington DC: The Government Accountability Office. https://www.gao. gov/products/HEHS-95-114. 


\section{Featured Articles}

---. 2009. Medicaid Preventative Services: Concerted Efforts Needed to Ensure Beneficiaries Receive Services. Washington DC: The Government Accountability Office. https://www.gao.gov/ assets/300/293989.pdf

---. 2019. Medicaid: Additional CMS Data and Oversight Needed to Help Ensure Children Receive Recommended Screenings. Washington DC: The Government Accountability Office. https://www. gao.gov/assets/710/700958.pdf

Halfon, Neal and Linnea Klee. 1987. "Health Services for California's Foster Children: Current Practices and Policy Recommendations." Pediatrics 80, no. 2 (August): 183-91.

Hillen, Thomas, and Leonie Gafson. 2015. "Why Good Placements Matter: Pre-Placement and Placement Risk Factors Associated with Mental Health Disorders in Pre-School Children in Foster Care." Clinical Child Psychology and Psychiatry 20 (3): 486-499. DOI: 10.1177/1359104514530733.

Hochstadt, Neil.J., Paula K. Jaudes, Deborah A. Zimo, and Jayne Schachter. 1987. “The Medical and Psychosocial Needs of Children Entering Foster Care." Child Abuse \& Neglect 11, no. 1 (January): 53-62. https://doi.org/10.1016/0145-2134(87)90033-0.

Jee, Sandra H., Richard P. Barth, Moira A. Szilagyi, Peter G. Szilagyi, Masahiko Aida, and Matthew M. Davis. 2006. "Factors Associated with Chronic Conditions Among Children in Foster Care." Journal of Health Care for the Poor and Underserved 17 (2): 328-41. https://doi.org/10.1353/ hpu.2006.0062

Lehmann, Brooke, Jocelyn Guyer and Kate Lewandowski. 2012. Child Welfare and the Affordable Care Act: Key Provisions for Foster Care Children and Youth Report. Washington DC: Georgetown University Health Policy Institute, Center for Children and Families. https://ccf.georgetown.edu/wp-content/ uploads/2012/07/Child-Welfare-and-the-ACA.pdf.

Leslie, K. Laurel, Jeanne N. Gordon, Lee Meneken, Kamila Premji, Katherine L. Michelmore, and William L. Ganger. 2005. "The Physical, Developmental, and Mental Health Needs of Young Children in Child Welfare by Initial Placement Type." Journal of Developmental \& Behavioral Pediatrics 26, no. 3 (June): $177-185$.

Lewis, James M., and Amelia E. Beatty. "Meeting The Healthcare Challenges For Children In Foster Care: A Survey Of West Virginia Pediatricians.” West Virginia Medical Journal 114, no. 2.

McGill, N. 2016. "Making Health Care a Priority for Children in the Foster Care System: Connecting to Care, Wherever Kids Are." The Nation's Health. Accessed January 25, 2020. http:// thenationshealth.aphapublications.org/content/46/7/1.2.

MACPAC (Medicaid and CHIP Payment and Access Commission). 2015. "The Intersection of Medicaid and Child Welfare." In June 2015 Reports to Congress on Medicaid and CHIP. Washington, DC: MACPAC. https://www.macpac.gov/publication/the-intersection-of-medicaid-and-childwelfare-2/.

---. n.d. “EPSDT in Medicaid.” EPSDT In Medicaid. Accessed April 5, 2019. https://www.macpac.gov/ subtopic/epsdt-in-medicaid/.

Pandve, Harshal T. 2014. "Quaternary Prevention: Need of the Hour." Journal of Family Medicine and Primary Care 3, no. 4 (December): 309-10.

Pires, Shiela A and Beth A. Stroul. 2013. Making Medicaid Work for Children in Child Welfare: Examples from the Field, edited by Taylor Hendricks. Washington DC: Center for Health Care Strategies. https://www.chcs.org/media/Making_Medicaid_Work.pdf.

Reilly, Thom. 2003. “Transition from Care: Status and Outcomes of Youth Who Age Out of Foster care.” Child Welfare 82 (6): 727-746. 
Ringeisen, Heather, Cecilia Casanueva, Mathew Urato, and Theodore Cross. 2008. "Special Health Care Needs Among Children in the Child Welfare System." Pediatrics 122, no. 1 (July): e232-41. https:// doi.org/10.1542/peds.2007-3778.

Rosenbaum, Sara. 2016. "When Old Is New: Medicaid's EPSDT Benefit at Fifty, and the Future of Child Health Policy: Medicaid’s EPSDT Benefit at Fifty." The Milbank Quarterly 94, no. 4 (2016): 716-19. https://doi.org/10.1111/1468-0009.12224.

---. 2017. "ACEs and Child Health Policy: The Enduring Case for EPSDT." Academic Pediatrics 17 (7): S34-35. https://doi.org/10.1016/j.acap.2017.03.010.

Rosenbaum, Sara, D. Richard Maurey, Peter Shin, and Julia Hidalgo. 2005. National Security and US Child Health Policy: The Origins and Continuing Role of Medicaid and EPSDT. Washington, DC: George Washington University, School of Public Health and Health Services. http://publichealth.gwu.edu/ departments/healthpolicy/CHPR/downloads/mil_prep042605.pdf

Rubin, David. n.d. Foster Children and the Health Care System. Testimony on behalf of the American Academy of Pediatrics, House Ways and Means Subcommittee on Income Security and Family Support Hearing. Accessed April 26, 2019. https://www.aap.org/en-us/advocacy-and-policy/ aap-health-initiatives/healthy-foster-care-america/Documents/fostercare_testimony_rubin. pdf\#search=testimony\%20david\%20Rubin.

Ruptier, Norma M. 1997. “Ensuring Health Care for Foster Children through Medicaid's EPSDT Program.” American Journal of Public Health 87 (2): 290-91.

Rutgers, The State University of New Jersey. n.d. "The Behavioral Research and Training Institute." University Behavioral Health Care. Accessed January 25, 2020. https:/ubhc.rutgers.edu/ education/brti-overview.xml.

Rutgers Health. n.d. "CCRTR Mission." Rutgers Health Children's Center for Resilience and Trauma Recovery. Accessed January 25, 2020. https://rukidsrresilient.org/

San Diego County. 2017. "Health Care Program for Children in Foster Care (HSPCFC)." Health and Human Services Agency. Last Modified June 28, 2017. Accessed January 25, 2020. https://www. sandiegocounty.gov/content/sdc/hhsa/programs/phs/child_health_disability_prevention_ program/children_in_foster_care.html

Simms, Mark D., Howard Duowitz, and Moira Szilagyi. 2000. "Health Care Needs of Children in the Foster Care System." Pediatrics 106 (4): 909-918.

Szilagyi Moira A., David S. Rosen, David Rubin, Sarah Zlotnick, The Council on Foster Care, Adoption and Kinship Care, the Committee on Adolescence, and the Council on Early Childhood. 2015. "Health Care Issues for Children and Adolescents in Foster Care and Kinship Care." Pediatrics 136 (4): e1142-1166. DOI: 10.1542/peds.2015-2656.

Takayama, John. I., Ellen Wolfe, and Kevin P. Coulter. 1998. "Relationship Between Reason for Placement and Medical Findings Among Children in Foster Care." Pediatrics 101, no. 2 (February): 201-7. https://doi.org/10.1542/peds.101.2.201.

Tennessee Department of Children's Services. 2015. State of Tennessee Department Of Children's Services Annual Progress And Services Report 2014-2015. Nashville: Tennessee Department of Children's Services. https://www.tn.gov/content/dam/tn/dcs/documents/quality_improvement/federalinitiatives/TN_DCS_APSR_FY_2015.pdf

Texas Department of Family and Protective Services. n.d. "Health Passport." Accessed December 26, 2019. https://www.dfps.state.tx.us/Child_Protection/Medical_Services/Health_Passport.asp.

Williams P. Gail, Marc Alan Lerner, AAP Council on Early Childhood, and AAP Council on School Health. 2019. “School Readiness." Pediatrics 144 (2): e20191766. https://doi.org/10.1542/peds.2019-1766. 
JAE-MARIE FERDINAND is a second-year Master of Public Policy candidate at the Trachtenberg School, focusing on health policy. She believes every child has the right to achieve their full potential. Jae-Marie is an Academic Pediatrician and Assistant Professor, on sabbatical from McGill University (Montreal, Canada). She received her Medical Degree from the University of Toronto. Jae-Marie completed her Pediatric Residency at McGill University and her Neonatology Fellowship at Harvard University and the University of Toronto. She has developed and directed programs to optimize the care for children with complex healthcare needs, and to teach medical trainees the advocacy and clinical skills to care for socially disadvantaged children. This past summer, Jae-Marie enjoyed her dream internship at Management Sciences for Health. Jae-Marie is a passionate advocate for all children and families, especially those who are vulnerable.

\section{ACKNOWLEDGEMENTS}

The author would like to start by thanking Professor Anne Markus for allowing her to follow her passion by analyzing this important subject. The author is forever grateful to the editors, Jacqueline Wheeler and Kendall Banks, for their patience, support, help and encouragement. They were her best cheerleaders! The author would also like to thank Professor Elizabeth Rigby, for sharing her insight and understanding of this complex subject, and encouraging her to view the combination of social and health policy analysis from different angles. In addition, the author would like to thank all of the healthcare and child welfare professionals, lawyers, politicians and the many people on the ground who advocate for children in foster care. Most importantly, the author would like to thank the foster children, themselves. The author is always humbled by their amazing resilience, often against the odds. 